\title{
O PROFESSOR COMO MEDIADOR DAS LEITURAS LITERÁRIAS NAS TURMAS DA EDUCAÇÃO INFANTIL
}

\author{
Amanda Natalia Brilhante ${ }^{1}$ \\ Bartira Angela Irineu dos Santos ${ }^{2}$ \\ Diogenes José Gusmão Coutinho ${ }^{3}$
}

RESUMO: Este trabalho, através da pesquisa bibliográfica, respaldado em autores como Machado (2002), Riter (2009) e Faria (2004), teve como objetivo compreender a importância da mediação como estimulo para a prática da leitura literária, as estratégias que o professor/mediador pode utilizar para tornar o momento da leitura mais significativo e a contribuição da mesma na formação dos alunos. Considerando o professor/mediador como meio para que através das estratégias de mediação o mesmo possa despertar o conhecimento, possibilitar e estimular a leitura na infância para formar adultos leitores, visto que não é apenas ler, mas compreender e entender o que é lido. Ao criar e recriar as maneiras de contar histórias o professor está sendo uma ponte para que as crianças desenvolvam além do hábito da leitura as suas habilidades de aprendizagem.

Palavras-Chave: Leituras literárias. Mediação. Educação Infantil.

ABSTRACT: This work, through bibliographic research, supported by authors such as Machado (2002), Riter (2009) and Faria (2004), aimed to understand the importance of mediation as a stimulus for the practice of literary reading, the strategies that the teacher / mediator can use it to make the moment of reading more meaningful and its contribution to the formation of the students. Considering the teacher / mediator as a means so that through mediation strategies it can awaken knowledge, enable and stimulate reading in childhood to form adult readers, since it is not just reading, but understanding and understanding what is read. By creating and recreating storytelling ways, the teacher is being a bridge for children to develop beyond their reading habits their learning skills.

Keywords: Literary readings. Mediation. Child education.

\footnotetext{
${ }^{\text {I }}$ Pedagoga pela Uninabuco. Pós-graduanda do curso de especialização em psicopedagogia institucional e clínica pela faculdade Alpha.

${ }^{2}$ Pedagoga pela Uninabuco. Pós-graduada do curso de especialização em Educação especial e Inclusiva pela Alpha. Faculdade. Pós-graduanda do curso de especialização em psicopedagogia institucional e clínica pela faculdade Alpha.

3 Doutor em biologia pela UFPE. Professor da faculdade alpha. Orientador do curso de especialização em psicopedagogia institucional e clínica da faculdade Alpha.
} 


\section{INTRODUÇÃO}

O presente artigo visa compreender o papel do professor como mediador das leituras literárias na educação infantil, levando em consideração a importância de como se trabalhar a mediação das leituras literárias em sala de aula através de diferentes estratégias de leituras na constituição do leitor e no seu desenvolvimento durante a infância. Tendo como investigação a pesquisa bibliográfica caracterizando a importância da literatura infantil desde suas origens e evolução, visto que as crianças na época do século XVII eram tratadas como adultos sem contato algum com atividades e leituras direcionadas a sua faixa etária, com a finalidade de moldar a criança de acordo com as expectativas dos adultos.

Com o passar do tempo a leitura ganha uma nova veste adotando um método de ensino que enfatiza a importância da leitura voltada para a infância com o objetivo de que a leitura passasse a ser então um ato de abertura para o mundo.

Partindo do pressuposto de que o professor/mediador tem um papel fundamental no estímulo à prática da leitura literária, percebeu- se a importância de pesquisar sobre o dito tema, uma vez que a leitura infantil é essencial para a aprendizagem e necessita de práticas assertivas que agucem a leitura e dê prazer ao ler. Tendo em vista que a partir do momento em que o leitor dá sentido aquilo que está lendo esse descobrirá o real objetivo pelo quanto é prazeroso e gostoso ler despertando o interesse pela leitura e aumentando o seu desejo de aprender.

Segundo Cosson (2012, p. 30):

$\mathrm{Na}$ escola, a leitura literária tem a função de nos ajudar a ler melhor, não apenas porque possibilita a criação do hábito da leitura ou porque seja prazerosa, mas sim, e sobretudo, porque fornece, como nenhum outro tipo de leitura faz, os instrumentos necessários para conhecer e articular com proficiência o mundo feito linguagem.

Assim, considerando a importância da leitura, uma vez que a mesma realizada com prazer desenvolve a imaginação, a escuta atenta e a linguagem das crianças. E como mediador é necessário que possamos oferecer aos nossos alunos o contato com o livro, fazendo com que o mesmo se sinta capaz de fazer a leitura através de suas próprias escolhas. Na visão de Kleiman (1998, p. 51),

O leitor proficiente faz escolhas baseando- se em predições quanto ao conteúdo do livro. Essas predições estão apoiadas no conhecimento prévio, tanto sobre o assunto (conhecimento enciclopédico), como sobre o autor, a época da obra (conhecimento 
social, cultural, pragmático) o gênero (conhecimento textual). Daí ser necessário que todo programa de leitura permita ao aluno entrar em contato com um universo textual amplo e diversificado.

Nesse sentido faz- se evidente compreender que a leitura infantil influencia motivando e estimulando a criança como um leitor ativo, fazendo com que o contato com os livros proporcione o prazer que a leitura propicia, adquirindo uma postura crítica e com probabilidade de tornar- se um adulto fluente das leituras literárias, e para que isso flua o professor/mediador precisa estar preparado e se apropriar de técnicas que torne o hábito da leitura um momento prazeroso e de descobertas.

\section{REVISÃO TEÓRICA}

\section{I HISTÓRICO DA LEITURA LITERÁRIA NA EDUCAÇÃO INFANTIL}

A literatura infantil, até o século XVII de um modo geral tinha apenas como intuito a educação das crianças no sentido moral para a vida em sociedade e a obediência, indicando o que era "bom" e o que era "mal" o que "podia" e "não podia" ser feito, sem determinação de faixa etária e sem qualquer outro tipo de direcionamento as crianças, visto que as crianças nessa época eram tratadas como adultos, sem contanto algum com atividades e leituras direcionadas atualmente às crianças (SILVA, 20II).

De acordo com Silva (2008, p.136):

Para pensar a literatura infantil, é necessário pensar no seu leitor: a criança. Até o século XVII, as crianças conviviam igualmente com os adultos, não havia um mundo infantil, diferente e separado, ou uma visão especial da infância. Não se escrevia, portanto para as crianças

É a partir do final do século XVII e início do século XVIII que a criança começa a ganhar espaço e visibilidade como criança de fato, deixando de ser vista como um mero adulto, despertando o interesse de escritores para a escrita de obras literárias com uma visão infantil, através de mudanças na escrita, no texto, imagens e no desfecho da história, pois agora o público deixa de ser um público específico e passa a ser de várias faixas etárias com características e necessidades diferentes.

Segundo Abramovich (1991, p. 33):

Há prazer de folhear um livro, colorido ou branco e preto [...] livros feitos para crianças pequenas, mas que podem encantar aos de qualquer idade, são, sobretudo experiências de olhar, de um olhar múltiplo, pois se vê com o olhar do autor e do 
olhador/leitor, ambos enxergando o mundo e os personagens de modo diferente. Conforme percebem o mundo. Saborear e detectar tanta coisa que nos cerca usando este instrumento nosso tão primeiro, tão detonador de tudo, a visão.

A partir do olhar diferenciado para a leitura direcionada às crianças, começaram a ser escritos os contos, fábulas e as histórias infantis visando não só a educação, mas a diversão, a imaginação, o lúdico, a linguagem, a interação, a sensibilidade, valores, comportamentos, assim como também jogos e brincadeiras. Escritores como: Ziraldo, Ruth Rocha, Monteiro Lobato, Maurício de Sousa, Eva Furnari, Ana Maria Machado entre outros autores, que impulsionaram e deram sentido a uma leitura adequada e prazerosa para o público infantil (SILVA, 20II).

Neste sentido, é notório que a leitura literária diante de todo seu contexto histórico de direcionamento aos pequeninos, conseguiu se solidificar no meio literário e trazer para a atualidade um sentido a leitura, pois um bom leitor precisa ser estimulado desde a sua infância para que crie o hábito e o prazer pela leitura.

\subsection{O PROFESSOR COMO MEDIADOR DA LEITURA LITERÁRIA}

Alguns autores defendem que, antes de formador de leitor, o professor deve ser um leitor ativo e não apenas repetir o discurso para as crianças que elas precisam ler, pois ler é importante (PASCOAL, 2009, p. 24).

O professor ele tem um papel fundamental na construção de novos saberes, sua responsabilidade é de grande importância, pois o mesmo necessita se adaptar- se as diferentes linguagens e criar oportunidades para além das situações educativas, transcendendo a sala de aula, sendo assim despertar o conhecimento, provocar reflexões, despertar o desejo de aprender, entre outros, para que a realização da construção de autonomia vise a contribuição para a construção de uma sociedade crítica e pensante.

A este respeito, Riter (2009) traz reflexões sobre sua prática de professor de Literatura e conclui que o professor/mediador deve adotar três faces que possibilitem uma melhor atuação como formador de leitor.

A primeira face apontada por ele seria o professor como contador de histórias. Para o autor seriam necessárias algumas características no ato de contar a história, como por exemplo, a escolha de histórias conhecidas pelo contador, pois isso facilitará um maior 
envolvimento do mediador na condução da leitura. Outra característica se deve ao fato do livro escolhido ser do gosto do professor/mediador, pois ao contá-la o aluno perceberá toda a paixão que o mediador sente ao ler o livro. Outra sugestão é iniciar e encerrar a contação de histórias com frases já conhecidas tais como, "era uma vez" ou "quem quiser que conte outra”. Essas fórmulas de abertura e de fechamento acabam favorecendo que a criança entenda que o jeito de tratar a linguagem nas situações de leitura é peculiar ao modo literário de lidar com a língua, portanto trazem significados importantes ao leitor.

A segunda face que o professor deve ter na percepção de Riter (2009) é de guia na biblioteca. O professor teria o papel de guiar o aluno neste ambiente com a finalidade de mudar a percepção sobre a biblioteca escolar, superando a visão equivocada de que este espaço é um mero depósito de livros, um local destinado ao castigo ou até mesmo como templo a ser conservado, mas não utilizado. E ao realizar esta tarefa de guia, o professor contribui para mudar essa percepção revelando assim, outras possibilidades - lugar de pesquisa; de descobertas de universos literários; para descobertas de novos autores, espaço de troca e de partilhas literárias.

O professor ao mediar ele se coloca entre o aluno e a aprendizagem e isso só acontece quando há uma quebra de paradigmas do professor como detentor de todo saber. Mediar é facilitar o processo de aprendizagem para que a formação se transforme em conhecimento. Ser uma ponte entre a literatura e a criança é uma prática diária na vida de um professor, pois trata- se de um ato muito importante para o aprendizado da criança, onde por meio da contação de histórias dos mais variados gêneros o professor contribuirá para fatores como a escrita, criatividade, imaginação, raciocínio e a interpretação. No entanto não é ser apenas a ponte, é guiar a criança e criar durante todo o percurso meios que tornem a leitura e a história prazerosa, divertida e muito atrativa.

O professor/ mediador pode utilizar meios que estimulem as crianças a terem uma relação ainda mais próxima com a literatura, como convidar as crianças a formarem uma roda, pois é muito importante que todas consigam se olhar e interagir, usar fantoches, fantasias, músicas, usar ferramentas tecnológicas, objetos relacionados a história para serem manuseados pelas crianças, a entonação da voz do professor diferenciando os personagens apresentados no livro, convidar as crianças para serem personagens, dar espaço para que elas 
também possam pegar e manusear o livro para que o momento da leitura se torne um estimulo a prática da leitura literária no cotidiano das crianças.

Quando o professor ele cria e recria maneiras de contar histórias ele está investindo na formação de crianças leitoras, apresentando a elas diversas maneiras de ver o mundo e como explorá-lo, conhecer os sentimentos e as diferentes culturas.

\subsection{A PREPARAÇÃO PARA A MEDIAÇÃO DO TEXTO LITERÁRIO}

Usar o texto literário na sala de aula é uma arte, pois envolve vários mecanismos para prender a atenção dos seus ouvintes. Mas não é somente isso, precisa encantar. E para isso, o educador precisa estar preparado utilizando- se de técnicas apropriadas para todo tipo de ouvinte, assim como utilizar recursos, espaço e tempo para atender melhor às suas necessidades.

Segundo Coelho (200o, p. 27).

A literatura infantil é antes de tudo, literatura; ou melhor, é arte: fenômeno de criatividade que representa o mundo, o homem, a vida, através da palavra. Funde os sonhos e a vida prática, o imaginário e o real, os ideais e sua possível/impossível realização...

A literatura infantil permite que o pequeno leitor participe de experiências de vida através da representação do mundo, ao fazer uma relação entre o maravilhoso e o real. Através da literatura é possível: aprender, refletir, questionar, comparar, investigar, imaginar, emocionar, divertir, desenvolver a sensibilidade estética e a expressão linguística, adquirir cultura

Desta forma, a literatura aguça na criança a imaginação, a criação e a fruição, ou seja, ela é o agente ideal para a formação de uma nova mentalidade, pois abre um leque de possibilidades para que a criança amplie seus conhecimentos e desenvolva suas habilidades cognitivas ao fazer uma ponte entre o real e o imaginário.

Para Abramovich (1997), a contação não pode ser feita de qualquer jeito, sem nenhum preparo. Pelo contrário, corre o risco de no meio desta, empacar ao pronunciar alguma palavra, fazer pausas em momentos errados ou mesmo perder o seu rumo e, certamente, a criança perceberá.

O professor precisa preparar a si mesmo através da sua bagagem de leitura na busca por conhecimento, ler o texto com antecedência, criar estratégias e técnicas que possibilitem 
a imaginação a partir da leitura, estar seguro e empenhado, pois isso irá refletir no momento da leitura do texto literário, ou seja, o mediador com sua experiência será um espelho para o aluno que está em busca de informação e de leituras que se assemelhem a sua vivência e sua personalidade, assim como também o mediador será um facilitador de experiência.

Segundo Santos (2009, p. 40):

Para ser um agente de leitura a pessoa tem primeiro que gostar de ler, ter vontade e compromisso social de compartilhar esse gosto e sua experiência de leitura com um outro tanto de gente, formando leitores em ambientes diversos como bibliotecas públicas municipais, escolas, fábricas, empresas, associações, comunidades e dentro das casas, no seio de famílias que abrem suas portas para que os livros e a leitura possam entrar em suas vidas.

Para que a mediação do professor, entre a literatura e as crianças, seja eficaz, é fundamental que a preparação do mediador se dê a partir de um relacionamento positivo com os leitores, ou seja, conhecer os alunos, investigar os gostos literários através de diálogos, adaptar-se ao ritmo da criança, incentivar a escolha do livro e selecionar livros que estejam de acordo com a faixa etária da turma. A ação de mediar leitura envolve observação, orientação e interação. $\mathrm{O}$ mediador deve ser, antes de tudo, um leitor que tem o papel de colocar-se como ponte entre o texto e o leitor. Nesse sentido, Garcia (2007, p. 95) afirma que o "mediador muitas vezes faz o percurso junto, ele mesmo é um sujeito em processo, alguém que vai formando leitor à medida que vai formando outros leitores. O mediador de leitura deve estar atento para os fatos e acontecimentos do seu cotidiano, conectado com os fatos da vida dos alunos que possam servir de mote para as conversas e para as propostas de leitura que realiza. Por isso, a interação com diferentes gêneros textuais, é importante, pois eles podem fornecer oportunidades para aprofundar discussões e conquistar leitores ainda reticentes quanto ao prazer de ler. A sedução para a leitura, por isso mesmo, envolve conhecimentos técnicos e de mundo, na medida em que exige do mediador sensibilidade para perceber o que está acontecendo no espaço social dos ouvintes e seus interesses.

Também é preciso levar em consideração o ambiente onde será realizada a leitura, pois deve ser preparado um ambiente aconchegante, decorado e atrativo para os momentos de leitura, fazer rodas de leitura, pois nas rodas todos conseguem se observar e visualizar os métodos utilizados para a mediação. Buscar na realidade dos alunos recursos que auxilie o professor a articular as histórias de vida do leitor com os textos escolhidos, visto que a leitura 
precisa ser avaliada como instrumento de aprendizagem, conhecimento e momento deleite.

Faria (2004) apresenta reflexões sobre as relações de prazer tanto emocional e intelectual que a literatura traz ao leitor, pois é muito mais que uma leitura, é uma caminhada em busca de conhecimento diante dos mais variados textos literários.

Há uma gama de possibilidades para se realizar a mediação do texto literário a partir da preparação do mediador que é o ponto principal para que a mediação tenha um efeito positivo e estimulante para que a prática da leitura literária seja aguçada no cotidiano dos alunos tanto no ambiente escolar quanto na sociedade.

Nessa perspectiva, a literatura infantil permite o contato da criança com uma pluralidade cultural, pois a mesma tem a capacidade de entreter, emocionar as crianças, e ao mesmo tempo, apresentar de maneira lúdica as narrativas e os diversos gêneros literários presentes nela. Por isso, a presença da literatura infantil na sala de aula é considerada pelos especialistas, referência para que o professor possa desenvolver nas crianças o gosto pela leitura por meio do convívio com a linguagem literária.

Diante das considerações acima, pode-se dizer que o contato com o texto literário contribui de forma única na formação do cidadão e na constituição do leitor crítico e consciente dos seus direitos e deveres diante da sociedade, tendo em vista que o texto literário convida o pequeno leitor a participar de um processo interativo de construção e reconstrução do conhecimento.

\subsection{O TEXTO LITERÁRIO: IMPORTANTE RECURSO PARA DESENVOLVIMENTO DO PRAZER DE LER}

Por meio das leituras de textos literários o leitor preenche as suas necessidades permitindo apropriar- se de uma atitude crítica em relação ao mundo que vive. Diante disso, é papel do professor estimular o aluno para que o mesmo aprenda a gostar de ler e sinta prazer na leitura.

É o leitor quem cria, constrói o sentido a partir de seus conhecimentos, em sua expectativa e em sua intenção de leitura. No caso do aluno, porém, a intensão é do professor. Quem deseja que a leitura seja feita porque é importante, necessária para a explicitação de um assunto, para a ampliação de um conhecimento, ou por qualquer outro motivo, é o professor. Só ele pode transformar o que precisa ser lido em algo significativo e prazeroso (BRAGA; SILVESTRE, 2009, p. 22). 
$\mathrm{Na}$ visão de Braga e Silvestre (2009) o professor com sua vasta bagagem de experiência tem a possibilidade de não só ler para o aluno, mas a partir de uma leitura preparada, com técnicas e objetos no auxílio da leitura ter a possibilidade de transformar a leitura em um momento e uma prática prazerosa, onde o aluno desenvolva o interesse pela literatura e aumente o seu desejo de aprender.

O professor ao propor uma leitura de texto literário deve possibilitar que o aluno se delicie em uma boa história e se envolva sem compromisso de atividades escolares, mas que consiga sentir prazer com a leitura e viagem no mundo literário, fazendo descobertas e adquirindo conhecimento.

Acerca da leitura, Machado (2002) pronuncia- se sobre a quantidade de obras literárias valiosas que temos, mas que infelizmente acabam sendo esquecidas. E que são recursos que possibilitariam ainda mais o desenvolvimento do aluno-leitor.

Segundo Machado (2002, p. 20):

Lendo uma história, de repente descobrimos nela umas pessoas que, de alguma forma, são tão idênticas a nós mesmos, que nos parecem uma espécie de espelho. (...). Alguns livros acabam nos ajudando a entender melhor o sentido de nossas próprias experiências.

O texto literário propicia que o leitor crie e recrie histórias, que faça questionamentos, deduções acerca do que o texto realmente que mostrar, comparações com possíveis semelhanças com a realidade, cultura e linguagem, o que acaba chamando a atenção do aluno-leitor e despertando um interesse pela busca de mais conhecimento e prazer nas leituras diárias.

Muito mais que ser um recurso de alfabetização, o texto literário é uma forma de lazer que contribui para aprendizagem do indivíduo, como a contação de histórias em rodas de conversa para o aluno recriar e colocar em prática a sua criatividade juntamente com seus colegas. É dar prazer a leitura, essência para ler variados textos e dar sentido a leitura.

\subsection{LER, COMPREENDER E APRENDER}

Inserir as crianças no mundo literário é também ser uma ponte para que haja a compreensão, aprendizagem e significado ao que está sendo lido e para isso é necessário que o professor auxilie o leitor a encontrar um sentido na leitura.

Solé (1998, p. 40) explana o seguinte: 
[...] a compreensão que cada um realiza depende do texto que tem à sua frente, mas também depende muito de outras questões, próprias do leitor, entre as quais gostaria de ressaltar pelo menos as seguintes: o conhecimento prévio para abordar a leitura, os seus objetivos e a motivação com respeito a essa leitura.

A leitura é uma ferramenta de construção e reconstrução do ser humano e alimentar a prática da leitura literária desperta a fantasia, criatividade, linguagem, gramática e a comunicação da criança, mediante isto o professor ao entrar em contato com o livro deve perguntar para si mesmo: o que posso trabalhar a partir desse livro? O que é um bom texto? O que é preciso fazer antes da leitura e depois da leitura? Essa atribuição deve ser realizada a partir do conhecimento prévio do professor, pois o leitor ele tem que interagir com o texto para se aproximar e entender de fato o que o autor quis passar, sem que sua imaginação seja ignorada.

Leitura, compreensão e aprendizagem principalmente na educação infantil é uma atividade construtiva e educada, pois trata-se dos primeiros contatos com a literatura e envolver as crianças nessa valiosa atividade é proporcionar a prática e o gosto pela mesma abrindo um "leque" de novas informações ao mesmo tempo que aguça o leitor a buscar conhecimento, pois como diz Freire (2010, p.47) "Ensinar não é transferir conhecimento, mas criar as possibilidades para sua produção ou construção."

A atividade de leitura do professor está dirigida pelos objetivos que pretendemos mediante ela, não é a mesma coisa ler para ver se o conteúdo interessou e a leitura deve ser continuada, ler quando procuramos uma determinada informação ou quando se é necessário formar uma ideia global do conteúdo para transmiti-la, a leitura feita pelo professor deve ser baseada em boas escolhas, no que será mais coerente com o momento, o conteúdo adequado para a faixa etária, na aula que será seguida da leitura... etc. são pontos assim que contribuem para a formação de futuros leitores literários.

Para que uma pessoa possa se envolver em uma atividade de leitura, é necessário que sinta que é capaz de ler, de compreender o texto que tem em mãos, tanto de forma autônoma como contando com a ajuda de outros mais experientes que atuam como suporte e recurso (SOLÉ, 1998, p. 42).

Seguindo este pensamento, é compreensível que assim como é necessário que aluno sinta que é capaz de fazer a leitura, também é necessário que o mediador transmita a confiança para o mesmo, pois isso de alguma forma faz diferença no que virar a seguir. A leitura feita a partir de um conteúdo que seja coerente com a idade de quem lê também é 
muito importante para a compreensão, pois está atendendo aquilo que a criança de determinada idade almeja e se interessa tendo em vista que a leitura acontece na decodificação da escrita e das imagens que estão presentes nas literaturas, com isso a criança tem uma linha de compreensão mais fácil do que se está lendo, ouvindo, vendo ou tocando.

[...] caberia ao professor um papel radicalmente diferente do que anteriormente exercia: de agente transformador de informações em selecionar dessas informações, seu decodificador, mostrando como descobri-las e selecioná-las e de que maneira transformá-las em saberes. (ANTUNES, 200I, p. 12).

Quando há um conjunto de estratégias que norteiam a leitura a criança atribui significado ao que leu, visto que um único texto pode ser interpretado de várias maneiras. As críticas, perguntas e interrupções na hora de ler estão no contexto da compreensão e no caminho que as leva a aprender.

Vale destacar a importância de o professor organizar um lugar na sala de aula que assegure às crianças o fácil acesso a várias obras e que sejam inseridos eventos de leitura de vários gêneros, utilizando materiais escritos diversos, levando os alunos a terem contato com variadas obras. Esses elementos contribuem para desenvolver a construção de hábitos leitores e consequentemente a inserção na cultura letrada.

Dessa forma, o professor deve ampliar as suas habilidades com a leitura na educação infantil, voltando o seu olhar para sua própria atuação enquanto professor desencadeador de posturas reflexivas perante a sua realidade, ou seja, ser "diferencial" em uma sociedade capitalista em que as desigualdades sociais vêm crescendo a cada dia.

\section{METODOLOGIA}

Embasado em fundamentos teóricos já publicados, o desenvolvimento deste artigo foi feito por meio de pesquisa bibliográfica de alguns autores pesquisadores sobre o assunto, tais como: Freire, Faria, Machado, dentre outros. Além de documental, artigos, revistas e sites acadêmicos, por meio de leituras, fichamentos e interpretações. De acordo com Gil (2002, p.44) "Pesquisa bibliográfica é desenvolvida com base em material já elaborado, constituído principalmente de livros e artigos científicos”. Concordando com o autor, foram necessárias explorações constituídas por estudos em livros e artigos científicos para obter uma pesquisa muito mais profunda e mais bem elaborada, pois segundo Gil (2002, p. 45) “A 
principal vantagem da pesquisa bibliográfica reside no fato de permitir a cobertura de uma gama de fenômenos muito mais ampla do que aquela que poderia pesquisar diretamente”.

Sendo assim, a partir da leitura desses autores podemos perceber o professor como mediador ativo de estimulo em relação ao aluno no papel de despertar o interesse e o gosto pelas leituras literárias, pois a mesma traz para a sala de aula o ensejo de conduzir as crianças a aprender com prazer, visto que a leitura de uma obra literária estimula a imaginação e proporciona a construção de novos caminhos que levam a mais conhecimento, representando o ato de ler, ampliação de vocabulários, o pensar, refletir e a participação social do leitor na cidadania o inserindo em uma sociedade letrada, pois isso proporciona a construção de habilidades linguísticas para a compreensão e interpretação de textos.

A pesquisa bibliográfica é aquela que se realiza a partir do registro disponível, decorrente de pesquisas anteriores, em documentos impressos, como livros, artigos, teses etc. Utiliza-se de dados ou de categorias teóricas já trabalhados por outros pesquisadores e devidamente registrados. Os textos tornam-se fontes dos temas a serem pesquisados. $O$ pesquisador trabalha a partir das contribuições dos autores dos estudos analíticos constantes dos textos (SEVERINO, 2007, p. 122).

\section{CONSIDERAÇÕES FINAIS}

O objetivo do presente trabalho foi compreender o papel do professor como mediador das leituras literárias na educação infantil, observando obras de autores que exploram a literatura e mostram o quanto a mesma é valiosa para o cotidiano das crianças, concluindo assim que a leitura literária desempenhada de forma significativa contribui positivamente para a formação de crianças e futuros adultos que gostam de ler.

A leitura é uma ferramenta de construção e reconstrução do conhecimento e inserir a criança no mundo literário é dar a oportunidade para que a mesma a partir da leitura aprenda ainda mais através da imaginação, do olhar, da escrita e da oralidade, apropriandose de uma atitude crítica em relação ao mundo.

Conhecer e colocar em prática estratégias para estimular a leitura e torna-la prazerosa é peça fundamental para que o mediador possa construir um sentido ao que é lido. 
Desta forma, entendemos que é preciso haver a interação do professor/mediador com o aluno e com o texto, de forma preparada, visto que a forma como a leitura literária é mediada interfere no interesse da criança.

\section{REFERÊNCIAS}

ABRAMOVICH, Fanny. Literatura Infantil: Gostosura e Bobices. Edit. Scipione $2^{\circ}$ Ed. São Paulo 199ı.

ABRAMOVICH, Fany. Literatura Infantil: Gostosuras e Bobices. $4^{-\underline{a}}$ ed., São Paulo: Scipione, 1997.

ANTUNES, Celso. Como desenvolver as competências em sala de aula. 2 ed. Petrópolis: Vozes, 2001.

BRAGA, Regina Maria; SILVESTRE, Maria de Fátima. Construindo o leitor competente: atividades de leitura interativa para sala de aula. São Paulo: Global, 2009.

COELHO, Nelly Novaes. Literatura Infantil: teoria, análise, didática. São Paulo: Moderna, 2000.

COSSON, Rildo. Letramento Literário: teoria e a prática. 2. ed. São Paul. Editora Contexto. 2012.

FARIA, Maria Alice. Como usar a literatura infantil na sala de aula. São Paulo: Contexto, 2004 .

FREIRE, Paulo. Pedagogia da autonomia: saberes necessários à prática educativa. 4I. São Paulo. Cortez.2oio.

GARCIA, Edson Gabriel (Org.). Prazer em ler

: registros esparços da emoção do caminhante nas lidas com a mediação da leitura. Instituto C\&a, 2007.

GIL, Antonio Carlos. Como Elaborar Projetos de Pesquisa. 4. ed. São Paulo: Atlas. 2008.

KLEIMAN, Ângela. Oficina de Leitura: Teoria e Prática. 6a. Ed. São paulo: Pontes. 1998.

MACHADO, Ana Maria. Como e por que ler os clássicos universais desde cedo. Rio de Janeiro: Objetiva, 2002.

PASCHOAL, Sônia Barreto de Novaes. Mediação cultura dialógica com crianças e adolescentes: oficinas de leitura e singularidade. Orientação Prof. Dr. Edmir Perrotti. São Paulo: ECA/USP, 2009. 
PETIT, Michele. A arte de Ler: Ou como Resistir a Adversidade. São Paulo. 34. 2009. Disponível em: < http://lelivros.love/book/download-a-arte-de-ler-ou-como-resistir-aadversidade-michele-petit-em-epub-mobi-e-pdf/ >

RITER, Caio. A formação do leitor literário em casa e na escola. São Paulo: Biruta, 2009. SANTOS, F. dos; Agentes de leitura. In. SANTOS, Fabiano dos; NETO, José Castilho Marques; RÖSING, Tânia M. K. (orgs.). Mediação de Leitura. Discussões e alternativas para formação de leitores. São Paulo: Global, 2009.

SEVERINO, Antonio Joaquim. Metodologia do trabalho científico. 23.ed. rev. E atual. São Paulo: Cortez, 2007.

SILVA, Aline Luiza. Trajetória da Literatura Infantil: Da Origem Histórica e do Conceito Mercadológico ao Caráter Pedagógico na Atualidade. Disponível em: 〈file://C:/Users/Edmilson/Downloads/234-I-759-I-Io-20100625.pdf〉

Acesso em: 25. Nov. 2019.

SILVA, Vitor Aparecido. Leitura Literária na Sala de Aula: Concepções dos Professores das Séries Iniciais.Disponível em: 〈file://C:/Users/Edmilson/Downloads/SilvaVitorAparecido_TCC\%2o(I).pdf〉 Acesso em: 21 Nov. 2019.

SOLÉ, Isabel. Estratégias de Leitura. 6aㅡ ed. Porto Alegre. Artmed. 1998. 